\title{
Potential sources of infection with selected zoonotic agents in the veterinary work environment - pilot studies
}

\author{
Angelina Wójcik-Fatla ${ }^{1, A-F} \oplus$, Jacek Sroka ${ }^{2, A-D \oplus}$, Violetta Zając ${ }^{1, A-D \oplus}$,

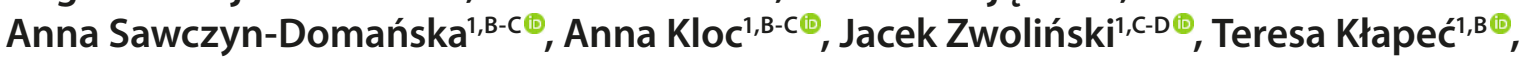 \\ Maria Bernadeta Studzińska ${ }^{3, B}{ }^{\oplus}$, Robert Chmura ${ }^{4, B} \oplus$, Jacek Dutkiewicz ${ }^{1, A, C-F \oplus}$ \\ ${ }^{1}$ Department of Health Biohazards and Parasitology, Institute of Rural Health, Lublin, Poland \\ 2 Department of Parasitology, National Veterinary Research Institute, Pulawy, Poland \\ ${ }^{3}$ Department of Parasitology and Invasive Diseases, Faculty of Veterinary Medicine, University of Life Sciences in Lublin, \\ Poland \\ ${ }^{4}$ Department of Epidemiology and Biostatistics, Institute of Rural Health, Lublin, Poland \\ A - Research concept and design, B - Collection and/or assembly of data, C - Data analysis and interpretation, \\ $D$ - Writing the article, E - Critical revision of the article, F - Final approval of article
}

Wójcik-Fatla A, Sroka J, Zając V, Sawczyn-Domańska A, Kloc A, Zwoliński J, Kłapeć T, Studzińska MB, Chmura R, Dutkiewicz J. Potential sources of infection with selected zoonotic agents in the veterinary work environment - pilot studies. Ann Agric Environ Med. 2020; 27(1): 146-150. DOI: $10.26444 /$ aaem/115363

\begin{abstract}
Ibstract
Introduction and Objective. The problem of occupational biohazards is very important, especially in the field of agriculture and in human and veterinary medicine. The aim of the study was to determine the potential sources of infection in veterinary professionals with selected zoonotic agents, including: Toxoplasma gondii, Giardia duodenalis, Leptospira spp., Cryptosporidium spp. and Coxiella burnetii.

Materials and Method. A total of 50 air samples from barns, piggeries and veterinary surgeries were examined for the presence of Leptospira spp. and C. burnetii DNA. Serum samples of 86 pigs and 80 cows were tested for the presence of antibodies to Leptospira spp. and to phase I and II C. burnetii antigens. Serum of 70 cats were tested for the presence of antibodies to T. gondii and 65 samples of cat faeces for the presence of T. gondii oocysts. The presence of G. duodenalis and Cryptosporidium spp. were examined in 50 of dog faeces and 50 of bovine faeces samples.

Results. DNA of Leptospira spp. was detected in 2 air samples from the piggeries (4\%). C. burnetii DNA was not found in any sample. Anti-Leptospira spp. antibodies were detected in 51 (59.3\%) of examined pigs. Neither anti-Leptospira spp. nor anti-C. burnetii antibodies were found among samples of bovine serum. Anti-T. gondii antibodies was found in 52 cat serum samples (74.3\%). Among samples of cat faeces, no T. gondii oocysts were detected. In one sample of cattle stool (2\%), G. duodenalis was detected and in another (2\%) - Cryptosporidium spp. G. duodenalis was detected in 7 samples (14\%) and Cryptosporidium spp. in 2 samples (2\%) of dog faeces.

Conclusions. The results of this study demonstrate the potential risk of infection with Leptospira spp. in veterinarians working with pigs. Veterinarians could be also be at risk of infection with T. gondii and G. duodenalis.
\end{abstract}

Key words

environment, Coxiella burnetii, Toxoplasma gondii, veterinarians, Leptospira spp, Cryptosporidium spp, Giardia duodenalis

\section{INTRODUCTION}

In the environment, the major sources of biohazards that pose a threat to humans and animals include sewage, waste, animal and plant products, dusts, human and animal excreta, clinical material, soil, water and bioaerosols. Biological agents are often transmitted by air droplet, air dust, through the skin and mucous membranes, or by some arthropods (ticks, fleas) [1]. The problem of occupational biological risk factors seem to be very important, although not fully understood, especially in the field of occupational medicine and public health. Veterinarians are among the occupations with the greatest exposure to extremely dangerous biological hazards, in this case zoonotic microorganisms causing severe infectious diseases. Thus, it is most important to take measures to learn

Address for correspondence: Angelina Wójcik-Fatla Department of Health Biohazards and Parasitology, Institute of Rural Health, Poland

E-mail: afatla@poczta.onet.pl

Received: 17.11.2019; accepted: 16.12.2019; first published: 30.12.2019 and, consequently, reduce the exposure of veterinarians to biohazard agents by taking preventive actions.

Leptospirosis is a zoonotic disease caused by various species of Leptospira spirochetes. Dogs, cats, pigs, domestic cattle, horses and wild animals may serve as the reservoir of Leptospira spp. and the bacteria reproduce in the kidneys [2]. Leptospirosis is one of the most widespread worldwide, and the number of cases is estimated at approximately 1.03 million annually (including 58,900 fatal cases) [3]. Primarily, leptospirosis outbreaks appear in regions with a tropical climate (such as the Pacific Islands region), where frequent floods and heavy rains contribute to the development of infection [4].

Toxoplasma gondii is a widely-distributed protozoan among animals and humans. It has sources in the wild environment into which oocysts are excreted by infected cats [5]. The occurrence of T. gondii in the natural environment is often associated with particular animal species occurring in a given area. For example, in Brazil, distribution of this parasite 
was identified as high among population of horses, mules and donkeys, where seropositive animals were observed on $95 \%$ of examined farms [6]. The main source of human infection, with the exception of contact with an infected cat, remains the ingestion of raw or undercooked meat. Research from Brazil confirmed the wide distribution and viability of Toxoplasma gondii tissue cysts in pig organs and commercial meat cuts [7]; T. gondii was also isolated from pigs destined for human consumption [8]. In Poland, T. gondii DNA was detected in $5.4 \%$ of examined retailed raw meat products [9]. Another transmission route is water contaminated with oocysts [10]. Consumption of the unpasteurized milk of infected animals (mainly sheep and goats) is a less common route for acquiring toxoplasmosis [11, 12].

Cryptosporidium spp. and Giardia duodenalis are defined as waterborne pathogens [13]. In China, both Cryptosporidium and Giardia have been detected in sewage and river waters, which confirms that both species circulate through the aqueous environment [14]. Human infection occurs through the digestive tract by consumption of food or water contaminated with the faeces of infected animals containing Cryptosporidium oocysts or Giardia cysts [15]. The prevalence of Cryptosporidium parvum in dairy calves has been confirmed in Argentina [16] and in Germany [15], and Giardia duodenalis among livestock and pets in Poland [17], and in pigs in China [18]. Therefore, the foodborne transmission of both parasites may be more common than until recently recognized.

Coxiella burnetii is a Gram-negative intracellular bacterium - etiological factor of Q fever - usually transmitted to humans by inhalation of contaminated aerosol [1] or by ticks bites. The pathogen has been detected not only in ticks from vegetation but also in ticks collected from livestock [19]. Domestic animals, such as sheep, goats and cattle, remain the main reservoir of Coxiella burnetii [20]. The animal source of infection could be products of abortion, faeces, urine, raw milk or cheeses made from unpasteurized milk [21]. In a recent study [22], the entire family of a seropositive veterinarian was examined, and one child aged 10 years was diagnosed with anti-Coxiella burnetii antibodies. The infection was most likely caused by consumption of sheep cheeses; thus, foodborne infection may not be excluded.

\section{OBJECTIVE}

The main aim of the study was to determine the potential sources of infection of veterinary professionals with selected zoonotic agents, including: Leptospira spp., Coxiella burnetii, Toxoplasma gondii, Giardia duodenalis and Cryptosporidium spp.

Leptospira spp. and Coxiella burnetii were isolated from the air of farms and veterinary surgeries and identified by PCR. Coxiella burnetii was also isolated from bovine placenta and likewise identified by PCR. The presence of antibodies against Leptospira spp. and Coxiella burnetii was additionally examined in pigs and cows.

Toxoplasma gondii was isolated from bovine placenta and identified by PCR. The stool samples of cats were tested for the presence of T. gondii oocysts. The presence of antibodies against Toxoplasma gondii was also examined in cats.

The stool samples of cows and dogs were tested for the presence of parasitic protozoans Giardia duodenalis and Cryptosporidium spp.

\section{MATERIALS AND METHOD}

A total of 50 air samples collected in cow barns (32 samples), piggeries (10 samples) and veterinary surgeries (8 samples) were examined for the presence of Leptospira spp. and Coxiella burnetii. Air samples were taken for 30 minutes on polypropylene and cellulose filters using an AS-50 sampler at the flow rate of $50 \mathrm{l} / \mathrm{min}$. DNA from the filter was isolated using Qiamp DNA Mini Kit (Qiagen, USA), according to the manufacturer's instructions. The detection of Coxiella burnetii DNA was based on amplification of the insertion sequence with primers IS1111f and IS1111r, described by Rolain and Raoult [23] and Subramanian et al. [24]. Detection of Leptospira spp. was performed according to Amutha et al. [25] using amplification by semi-nested PCR based on the fragment of LipL32 gene [26].

Serum samples of pigs and cattle from the Lublin province were supplied by veterinarians who collected blood from livestock as a part of statutory monitoring. A total of 86 pig and 80 bovine blood samples were obtained for this study. The commercial immunoenzymatic tests (ELISA) were used for testing serum samples for the presence of specific antibodies to Leptospira spp. antigens (VetLine Leptospira, NovaTec Immundiagnostica $\mathrm{GmbH}$, Germany), and to phase I and phase II Coxiella burnetii antigens (VetLine Coxiella Phase 1 and Phase 2 NovaTec Immundiagnostica GmbH, Germany).

Serum samples of 70 cats were supplied by veterinarians and were taken during other veterinary-medical activities requiring blood collection from the cat. A questionnaire containing information about the cats' living style was completed and supplied together with the serum samples. The commercial indirect immunofluorescence test (IFA) was used for testing the serum samples for the presence of specific antibodies to Toxoplasma gondii (Fuller Laboratories, USA) according to the manufacturer's instructions. Simultaneously, 65 samples of cat faeces were tested for the presence of Toxoplasma gondii oocysts [27].

Fragments of placenta after the miscarriage of cows were provided by veterinarians from Lublin province. A total of 27 placenta were examined for the presence of Toxoplasma gondii DNA. From each placenta, 10 fragments were acquired. DNA from 270 samples were isolated by Qiamp DNA Mini Kit, according to the tissue protocol. Detection of Toxoplasma gondii DNA was based on the amplification of the B1 fragment gene, according to Grigg and Boothroyd [28]. Detection of Coxiella burnetii DNA was performed as described previously.

A total of 50 samples of dog faeces and 50 samples of bovine faeces were examined for the presence of Giardia duodenalis cysts and Cryptosporidium spp. oocysts using direct fluorescent antibody (DFA) commercial test (Aqua-Glo ${ }^{\text {Tm }} \mathrm{G} / \mathrm{C}$ Direct Comprehensive Kit, Waterborne Inc., USA). Samples of bovine faeces were collected in cowsheds located in villages in the Lublin microregion., and samples of dog faeces collected in the urban and rural areas of the Lublin microregion.

The results were subjected to statistical analysis with Student's t-test and Pearson test for correlation, using Statistica v. 6.0 package (Statsoft, Tulsa, OK, USA). P-value $<0.05$ was assumed as significant. 


\section{RESULTS}

Prevalence of Leptospira spp. and Coxiella burnetii in farm air. DNA of Leptospira spp. was detected in two air samples from the piggeries (4.0\% of total samples and $33.3 \%$ of the samples taken in the piggery). Coxiella burnetii DNA was not found in the examined samples.

Serological response of pigs and cows to Leptospira spp. and Coxiella burnetii. Anti-Leptospira spp. antibodies were detected in 51 of 86 (59.3\%) examined pigs. Neither antiLeptospira spp. nor anti-Coxiella burnetii antibodies were detected in 80 samples of bovine sera.

Serological response of cats to Toxoplasma gondii occurrence of $T$. gondii oocysts in cat faeces. Most of examined cats belonged to the European breed (76.5\%). Specific anti-Toxoplasma gondii antibodies were found in 52 of 70 examined cat serum samples (74.3\%). Antibodies of IgG class were detected in $71.4 \%$ samples, whereas those of the IgM class - only in $31.4 \%$ samples $(\mathrm{P}<0.001)$. In 20 cats $(28.6 \%)$ antibodies of both IgM and IgG class. Positive results were more frequent in females (82.1\%) than in males $(60.7 \%)$ and the difference was nearly significant $(\mathrm{P}=0.06)$. An increase was observed in the percentage of seropositive animals with increase in their age, from $50.0 \%$ for cats below 1 year old, up to $74.4 \%$ for those between 1 5 -years-old, $76.9 \%$ for those between 5 - 10-years-old, and finally, $100 \%$ for those above 10 -years-old. The correlation between age and seropositivity proved to be significant $(\mathrm{P}<0.05)$. A similar distinct increase in seropositivity was also observed with relation to cats' habits (animals kept indoors reacted positively in $53.8 \%$, freely moving in $73.7 \%$ and feral in 91.7\%); the correlation in this case was also significant $(\mathrm{P}<0.05)$. A higher percentage of positive samples was found among cats living in the countryside (83.8\%) than in the city (52.2\%), and the difference proved to be significant $(\mathrm{P}<0.01)$. Positive results were found insignificantly more often in sterilized cats (76.5\%) compared to those not sterilized (66.7\%; P>0.05). Anti-T. gondii antibodies were significantly $(\mathrm{P}<0.05)$ more common in unvaccinated animals $(86.8 \%)$ then in those vaccinated against rabies and/or other viral diseases (58.6\%). Nevertheless, in $86.5 \%$ of seropositive cats the owners and veterinarians did not report any symptoms.

Among 65 examined samples of cat faeces, no Toxoplasma gondii oocysts were detected.

Prevalence of Toxoplasma gondii and Coxiella burnetii in bovine placenta. In 270 examined samples of bovine placenta, no Toxoplasma gondii or Coxiella burnetii DNA were detected.

Prevalence of Giardia duodenalis and Cryptosporidium spp. in bovine stool samples. Among 50 cattle stool samples examined, in one sample (2.0\%) Giardia duodenalis cysts were detected and in another $(2.0 \%)$ the presence of Cryptosporidium spp. oocysts. A positive Giardia duodenalis sample was collected in a barn housing 60 dairy cows, 5 - 7-years-old, which were not moved to pasture. A Cryptosporidium spp. positive sample was collected in a cowshed with 20 dairy cows and calves.
Prevalence of Giardia duodenalis and Cryptosporidium spp. in canine stool samples. Among 50 samples of dog faeces examined, in 7 (14.0\%) Giardia duodenalis cysts were detected, and in $2(4.0 \%)$ Cryptosporidium spp. oocysts. In one stool sample (2.0\%), Cryptosporidium spp. and Giardia duodenalis parasites were found simultaneously. All dogs in which parasites were detected came from an urban area, in which 23 samples ( $46 \%$ of the total) were collected. The prevalence of parasites in urban area was significantly higher compared to rural area $(16 \%$ vs. $0 \%$; $<<0.04)$.

\section{DISCUSSION}

In the presented study, no Coxiella burnetii DNA was found in the air samples, while in two samples of air collected on pig farms, the presence of Leptospira spp. was detected. Due to the fear of farm owners of African swine fever, it was not possible to collect air samples from large pig farms. The samples were taken only in several small piggeries, where animals were kept for breeders' own use. The percentage of positive air samples in these piggeries was high (33.3\%) but because of small number of total samples examined this result needs confirmation by further studies. Nevertheless, the results obtained in the current study which

Indicate the possibility of airborne infection of veterinarians with Leptospira in home piggeries are supported by the high prevalence of anti-Leptospira antibodies found in pigs in this study, as well as by a considerable percentage of seropositive results among veterinary surgeons (16.9\%), as stated by Wójcik-Fatla et al. [22]. Infection with Leptospira may occur by the penetration of spirochetes through damaged skin, conjunctiva and mucous membranes [29], by the inhalation of bacteria-containing aerosol [30], by consumption of contaminated water [26], and probably also by tick bite [31].

In the current study, anti-Leptospira spp. antibodies were detected in $59.3 \%$ of the pigs tested, which is a high prevalence, 2-3 times higher compared to similar studies performed in Italy [32] and Germany [33], and close to that reported by Cruz-Romero et al. from small households in Mexico [34].

In contrast, in the current study, no antibodies were founf against Leptospira spp. in cattle, unlike in other countries, such as Italy [35] and France [36]. Thus, the prtesented pilot study seems to indicate that in Poland exposure to pigs is mainly associated with the threat of veterinarians contracting leptospirosis. It would be therefore reasonable to introduce prophylactic diagnostic tests to detect anti-Leptospira spp. antibodies in veterinarians, both in the initial phase of employment and during the course of their professional work. Vaccination may be another solution to prevent leptospirosis which, in the case of cattle, is already used in New Zealand [37].

In the serological study of cattle, the authors of the current study did not find antibodies against Coxiella burnetiid, which corresponds with the negative results of air sampling. To-date, seropositive results in the study of Q fever in cattle have been obtained mainly in Asian countries and in South America $[38,39]$.

In the study of cat sera for the presence of antibodies against $T$. gondii, positive results were obtained in almost $75 \%$ of cases. This result is in agreement with earlier serological studies [40] and with the well-established view on the main role of the cat as a definitive host of $T$. gondii, excreting 
infective oocysts into soil and water [5]. In the presented study, a distinct increase of seroprevalence was found with cats' age in up to $100 \%$ in animals more than 10 -years-old. Similar results were obtained by Esteves et al. [41]. In the presented study, no oocysts of T. gondii were found in the samples of cat faeces. This may be related to the fact that cats expel oocysts into the environment, on average, for a period of 1-2 weeks, most often only once during their entire life. Nabi et al. demonstrated that the percentage of tested cats that expel oocysts does not usually exceed 2\% [42].

The current study on the occurrence of Toxoplasma gondii and Coxiella burnetii in samples of bovine placenta produced negative results. However, there were limitations to the study: the relatively low number of samples, and the fact that the placenta of sheep and goats - well-known hosts of both pathogens, in particular C. burnetiid - were not examined. Thus, despite the negative results obtained, the possibility of veterinarians' infection at birth reception cannot be ruled out, especially when working with other farm animals (sheep, goats).

The authors' coproscopic studies on the prevalence of Giardia duodenalis cysts and Cryptosporidium spp. oocysts in the faeces of cows and dogs, showed a low incidence of parasites in cows and a distinctly greater incidence in dogs, especially with regard to the incidence of Giardia duodenalis in dogs living in an urban environment.

\section{CONCLUSION}

This study on the occurrence of five zoonotic pathogens (Leptospira spp., Coxiella burnetii, Toxoplasma gondii, Giardia duodenalis, Cryptosporidium spp.) in various elements of veterinarians' working environment demonstrated the potential risk of infection with Leptospira spp. in veterinarians working with pigs. Thus, the application of preventive measures against leptospirosis, such as serological monitoring and/or vaccination, seems to be reasonable. Veterinarians could also be at risk of infection with Toxoplasma gondii on contact with cats and cat faeces, as well as at risk of infection with Giardia duodenalis on contact with dog faeces.

\section{Acknowledgements}

This study has been based on the results of Phase IV of the National Programme for the Improvement of Safety and Working Conditions (2017-2019) financed by the Ministry of Science and Higher Education/the National Centre for Research and Development and coordinated by the Central Institute for Labour Protection-National Research Institute (agreement No. TP-54/2017/PW-PB, Project No. II.N.22).

\section{REFERENCES}

1. Dutkiewicz J, Cisak E, Sroka J, Wójcik-Fatla A, Zając V. Biological agents as occupational hazards - selected issues. Ann Agric Environ Med. 2011; 18(2): 286-293.

2. Baer R, Turnberg W, Yu D, Wohrle R. Leptospirosis in a small animal veterinarian: reminder to follow standardized infection control procedures. Zoonoses Public Health. 2010; 57(4): 281-284.

3. Costa F, Hagan JE, Calcagno J, Kane M, Torgerson P, Martinez-Silveira MS, et al. Global Morbidity and Mortality of Leptospirosis: A Systematic Review. PLoS Negl Trop Dis. 2015; 9(9): e0003898.
4. Guernier V, Goarant C, Benschop J, Lau CL. A systematic review of human and animal leptospirosis in the Pacific Islands reveals pathogen and reservoir diversity. PLoS Negl Trop Dis. 2018; 14:12(5): e0006503.

5. Dubey JP. The history of Toxoplasma gondii-the first 100 years. J Eukaryot Microbiol. 2008; 55(6): 467-475.

6. Munhoz AD, Souza MA, Costa SCL, Freitas IS, Silva AND, Lacerda LC, et al. Factors associated with the distribution of natural Toxoplasma gondii infection among equids in Northeastern Brazil. Rev Bras Parasitol Vet. 2019; 28(2): 283-290.

7. Alves BF, Oliveira S, Soares HS, Pena HFJ, Conte-Junior CA, Gennari SM. Isolation of viable Toxoplasma gondii from organs and Brazilian commercial meat cuts of experimentally infected pigs. Parasitol Res. 2019; 118(4): 1331-1335.

8. Miura AC, de Barros LD, Ferreira FP, Neto JMF, Sicupira Franco PML, et al. Genotyping of Toxoplasma gondii isolated from pigs for human consumption. Parasitol Res. 2019; 118(5): 1593-1599.

9. Sroka J, Bilska-Zając E, Wójcik-Fatla A, Zając V, Dutkiewicz J, Karamon J, Piotrowska W, Cencek T. Detection and molecular characteristics of Toxoplasma gondii DNA in retail raw meat products in Poland. Foodborne Pathog Dis. 2019; 16(3): 195-204.

10. Galvani AT, Christ APG, Padula JA, Barbosa MRF, de Araújo RS, Sato MIZ, et al. Real-time PCR detection of Toxoplasma gondii in surface water samples in São Paulo, Brazil. Parasitol Res. 2019; 118(2): 631-640.

11. Bezerra M, Kim PC, Moraes ÉP, Sá SG, Albuquerque PP, Silva JG, et al. Detection of Toxoplasma gondii in the milk of naturally infected goats in the Northeast of Brazil. Transbound Emerg Dis. 2015: 62(4): 421-424.

12. Sroka J, Kusyk P, Bilska-Zając E, Karamon J, Dutkiewicz J, WójcikFatla A, Zając V, Stojecki K, Różycki M, Cencek T. Seroprevalence of Toxoplasma gondii infection in goats from the south-west region of Poland and the detection of T. gondii DNA in goat milk. Folia Parasitol. 2017; 64: 023.

13. Xiao L, Feng Y. Molecular epidemiologic tools for waterborne pathogens Cryptosporidium spp. and Giardia duodenalis. Food Waterborne Parasitol. 2017; 8-9: 14-32.

14. Ma L, Zhang X, Jian Y, Li X, Wang G, Hu Y, et al. Detection of Cryptosporidium and Giardia in the slaughterhouse sewage and river waters of the Qinghai Tibetan plateau area (QTPA), China. Parasitol Res. 2019; 118(7): 2041-2051.

15. Holzhausen I, Lendner M, Göhring F, Steinhöfel I, Daugschies A. Distribution of Cryptosporidium parvum gp60 subtypes in calf herds of Saxony, Germany. Parasitol Res. 2019; 118(5): 1549-1558.

16. Lombardelli JA, Tomazic ML, Schnittger L, Tiranti KI. Prevalence of Cryptosporidium parvum in dairy calves and GP60 subtyping of diarrheic calves in central Argentina. Parasitol Res. 2019; 118(7): 2079-2086.

17. Stojecki K, Sroka J, Cencek T, Dutkiewicz J. Epidemiological survey in Łęczyńsko-Włodawskie Lake District of eastern Poland reveals new evidence of zoonotic potential of Giardia intestinalis. Ann Agric Environ Med. 2015b;22(4):594-8.

18. Zhang HJ, Song JK, Wu XM, Li YH, Wang Y, Lin Q, et al. First report of Giardia duodenalis genotypes in Zangxiang pigs from China. Parasitol Res. 2019; 118(7): 2305-2310.

19. Abdelkadir K, Palomar AM, Portillo A, Oteo JA, Ait-Oudhia K, Khelef D. Presence of Rickettsia aeschlimannii, 'Candidatus Rickettsia barbariae' and Coxiella burnetii in ticks from livestock in Northwestern Algeria. Ticks Tick Borne Dis. 2019; 10(4): 924-928.

20. Porter SR, Czaplicki G, Mainil J, Guattéo R, Saegerman C. Q Fever: current state of knowledge and perspectives of research of a neglected zoonosis. Int J Microbiol. 2011; 2011: 248418.

21. Barandika JF, Alvarez-Alonso R, Jado I, Hurtado A, García-Pérez AL. Viable Coxiella burnetii in hard cheeses made with unpasteurized milk. Int J Food Microbiol. 2019; 303: 42-45.

22. Wójcik-Fatla A, Sroka J, Zając V, Zwoliński J, Sawczyn-Domańska A, Kloc A, et al. Study on Toxoplasma gondii, Leptospira spp., Coxiella burnetii and Echinococcus granulosus infection in veterinarians from Poland. J Vet Res. 2018; 62(4): 477-483.

23. Rolain JM, Raoult D. Molecular detection of Coxiella burnetii in blood and sera during Q fever. QJM. 2005; 98(8): 615-617.

24. Subramanian G, Sekeyova Z, Raoult D, Mediannikov O. Multiple tickassociated bacteria in Ixodes ricinus from Slovakia. Ticks Tick Borne Dis. 2012; 3(5-6): 406-410.

25. Amutha R, Chaudhury P, Garg AP, Vasan P, Cheema PS, Srivastava SK. Cloning and sequence analysis of the gene encoding LipL32 of Leptospira interrogans serovar Sejroe. Vet Res Commun. 2007; 31(5): 513-519. 
26. Wójcik-Fatla A, Zając V, Wasiński B, Sroka J, Cisak E, Sawczyn A, et al. Occurrence of Leptospira DNA in water and soil samples collected in eastern Poland. Ann Agric Environ Med. 2014; 21(4): 730-732.

27. Sroka J, Karamon J, Dutkiewicz J, Wójcik-Fatla A, Cencek T. Optimization of flotation, DNA extraction and PCR methods for detection of Toxoplasma gondii oocysts in cat faeces. Ann Agric Environ Med. 2018; 25(4): 680-685.

28. Grigg ME, Boothroyd JC. Rapid identification of virulent type I strains of the protozoan pathogen Toxoplasma gondii by PCR restriction fragment length polymorphism analysis at the B1 gene. J Clin Microbiol. 2001; 39(1): 398-400.

29. Wynwood SJ, Graham GC, Weier SL, Collet TA, McKay DB, Craig SB. Leptospirosis from water sources. Pathog Glob Health. 2014; 108(7): 334-338.

30. Doudier B, Garcia S, Quennee V, Jarno P, Brouqui P. Prognostic factors associated with severe leptospirosis. Clin Microbiol Infect. 2006; 12(4): 299-300.

31. Wójcik-Fatla A, Zając V, Cisak E, Sroka J, Sawczyn A, Dutkiewicz J. Leptospirosis as a tick-borne disease? Detection of Leptospira spp. in Ixodes ricinus ticks in eastern Poland. Ann Agric Environ Med. 2012; 19(4): 656-659.

32. Bertelloni F, Turchi B, Vattiata E, Viola P, Pardini S, Cerri D, et al. Serological survey on Leptospira infection in slaughtered swine in North-Central Italy. Epidemiol Infect. 2018; 146(10): 1275-1280.

33. Strutzberg-Minder K, Tschentscher A, Beyerbach M, Homuth M, Kreienbrock L. Passive surveillance of Leptospira infection in swine in Germany. Porcine Health Manag. 2018; 4: 10.

34. Cruz-Romero A, Alvarado-Esquivel C, Romero-Salas D, Alvarado-Félix ÁO, Sánchez-Montes S, Hernández-Tinoco J, et al. Seroepidemiology of Leptospira Infection in Backyard Pigs in Durango State, Mexico. Eur J Microbiol Immunol. 2018; 8(3): 87-90.

35. Tagliabue S, Figarolli BM, D’Incau M, Foschi G, Gennero MS, Giordani $\mathrm{R}$, et al. Serological surveillance of Leptospirosis in Italy: two year national data (2010 2011). Vet Ital. 2016; 52(2): 129-138.

36. Ayral FC, Bicout DJ, Pereira H, Artois M, Kodjo A. Distribution of Leptospira serogroups in cattle herds and dogs in France. Am J Trop Med Hyg. 2014; 91(4): 756-759.

37. McLean M, Ruscoe Q, Kline T, King C, Nesdale A. A cluster of three cases of leptospirosis in dairy farm workers in New Zealand. N Z Med J. 2014; 127(1388): 13-20.

38. Dhaka P, Malik SS, Yadav JP, Kumar M, Baranwal A, Barbuddhe SB, et al. Seroprevalence and molecular detection of coxiellosis among cattle and their human contacts in an organized dairy farm. J Infect Public Health. 2019; 12(2): 190-194.

39. Eraso-Cadena MP, Molina-Guzmán LP, Cardona X, Cardona-Arias JA, Ríos-Osorio LA, Gutierrez-Builes LA. Serological evidence of exposure to some zoonotic microorganisms in cattle and humans with occupational exposure to livestock in Antioquia, Colombia. Cad Saude Publica. 2018; 34(10): e00193617.

40. Sroka J, Karamon J, Dutkiewicz J, Wojcik-Fatla A, Zając V, Cencek T. Prevalence of Toxoplasma gondii infection in cats in southwestern Poland. Ann Agric Environ Med. 2018; 25(3): 576-580.

41. Esteves F, Aguiar D, Rosado J, Costa ML, de Sousa B, Antunes F, et al. Toxoplasma gondii prevalence in cats from Lisbon and in pigs from centre and south of Portugal. Vet Parasitol. 2014; 200(1-2): 8-12.

42. Nabi H, Rashid MI, Islam S, Bajwa AA, Gul R, Shehzad W, et al. Prevalence of Toxoplasma gondii oocysts through Copro-PCR in cats at Pet Center (UVAS), Lahore, Pakistan. J Pak Med Assoc. 2018; 68(1): $115-118$. 